\title{
Central precocious puberty: revisiting the diagnosis and therapeutic management
}

Vinícius Nahime Brito', Angela Maria Spinola-Castro', Cristiane Kochi², Cristiane Kopacek2, Paulo César Alves da Silva', Gil Guerra-Júnior²

\begin{abstract}
Clinical and laboratory diagnosis and treatment of central precocious puberty (CPP) remain challenging due to lack of standardization. The aim of this revision was to address the diagnostic and therapeutic features of CPP in Brazil based on relevant international literature and availability of the existing therapies in the country. The diagnosis of CPP is based mainly on clinical and biochemical parameters, and a period of follow-up is desirable to define the "progressive" form of sexual precocity. This occurs due to the broad spectrum of pubertal development, including isolated premature thelarche, constitutional growth and puberty acceleration, progressive and nonprogressive CPP, and early puberty. Measurement of basal and stimulated LH levels remains challenging, considering that the levels are not always in the pubertal range at baseline, short-acting $\mathrm{GnRH}$ is not readily available in Brazil, and the cutoff values differ according to the laboratory assay. When CPP is suspected but basal LH values are at prepubertal range, a stimulation test with short-acting or long-acting monthly $\mathrm{GnRH}$ is a diagnostic option. In Brazil, the treatment of choice for progressive CPP and early puberty is a long-acting $\mathrm{GnRH}$ analog $(\mathrm{GnRHa})$ administered once a month or every 3 months. In Brazil, formulations of $\mathrm{GnRHa}$ (leuprorelin and triptorelin) are available and commonly administered, including 1-month depot leuprorelin $3.75 \mathrm{mg}$ and $7.5 \mathrm{mg}$, 1-month depot triptorelin $3.75 \mathrm{mg}$, and 3-month depot leuprorelin $11.25 \mathrm{mg}$. Monthly or 3-month depot $\mathrm{GnRHa}$ are effective and safe to treat CPP. Arch Endocrinol Metab. 2016;60(2):163-72
\end{abstract}

Keywords

Precocious puberty; sexual maturation; gonadotropin-realising hormone; luteinizing hormone; long-acting GnRH analog
1 Departamento de Endocrinologia Pediátrica, Sociedade Brasileira de Endocrinologia e Metabologia (SBEM), Rio de Janeiro, RJ, Brasil ${ }^{2}$ Departamento de Endocrinologia, Sociedade Brasileira de Pediatria (SBP), Rio de Janeiro, RJ, Brasil

Correspondence to:

Gil Guerra-Júnior

Departamento de Pediatria,

Faculdade de Ciências Médicas, Universidade Estadual de Campinas Rua Tessália Vieira de Camargo, 126 Cidade Universitária "Zegferino Vaz" 13083-887 - Campinas, SP, Brasil gilguer@fcm.unicamp.br

Received on Feb/12/2016 Accepted on Mar/10/2016

DOI: 10.1590/2359-3997000000144

\section{INTRODUCTION}

$\mathrm{P}$ uberty is a period of physical, hormonal, and psychological transition from childhood to adulthood, with accelerated linear growth and achievement of reproductive function. It is a complex and multifactorial process that includes genetic, metabolic, environmental, ethnic, geographic, and economic factors and results in reactivation of the hypothalamic-pituitary-gonadal (HPG) axis. An effective pubertal onset requires pulsatile hypothalamic secretion of $\mathrm{GnRH}$ stimulating the secretion of gonadotropins by the anterior pituitary gland ( $\mathrm{LH}=$ luteinizing hormone and $\mathrm{FSH}=$ folliclestimulating hormone). Gonadotropins stimulate the gonads and exert a negative feedback effect on the hypothalamus, whereas gonadal steroids $(\mathrm{T}=$ testosterone, produced by the testis, and E2 = estradiol, produced by the ovaries) inhibit both hypothalamus and anterior pituitary gland. This process is named gonadarche (1-3).

Gonadarche is often preceded by adrenarche, a process ACTH-independent (adrenocorticotropic hormone) and responsible for the secretion of androgens (DHEA $=$ dehydroepiandrosterone and DHEAS = DHEA sulfate) by the adrenal zona reticularis. Adrenarche is clinically characterized by development of axillary odor, pubic hair, and skin oiliness, whereas in gonadarche the initial clinical manifestation is thelarche in girls and a bilateral increase in testicular volume in boys (4).

The classical definition of precocious puberty is the development of secondary sexual characteristics before the age of 8 years or menarche before the age of 9 years in girls and any secondary sexual characteristic before the age of 9 years in boys. However, recent epidemiological studies have suggested that the initial pubertal age is decreasing mainly in girls $(5-7)$, but also in boys $(8,9)$. 


\section{CLASSIFICATION OF PRECOCIOUS PUBERTY}

Precocious puberty is classified according to the underlying physiopathological process (10) in:

- Variants of normal pubertal development: isolated forms of thelarche, pubarche, or vaginal bleeding due or not to a hormonal etiology;

- Central precocious puberty (CPP), gonadotropin-dependent precocious puberty, or true precocious puberty: early maturation of the HPG axis;

- Peripheral precocious puberty, or gonadotropin-independent precocious puberty, or pseudoprecocious puberty: excessive secretion of gonadal sex hormones or adrenal hormones from a genetic or tumoral etiology, germ cell tumors secreting hCG (human chorionic gonadotropin - exclusively in boys), or an exogenous source.

\section{PARTICIPANTS AND OBJECTIVE}

There were 6 participants chosen for their expertise in pediatric and adult endocrinology. Therefore, a meeting was organized in Sao Paulo, Brazil, in October 2015, with representation from Brazilian Society for Endocrinology and Metabolism and Brazilian Pediatric Society, Departments of Pediatric Endocrinology, to examine current data relevant to the diagnosis and therapeutic management of children with CPP. This revision presents a summary of essential issues on this topic.

The aim of this revision was to address the diagnosis and therapeutic management of CPP based on relevant international literature and availability of the existing medications in Brazil.

\section{CENTRAL PRECOCIOUS PUBERTY}

\section{Etiology}

The main etiologies of CPP are listed in Table 1 (1015). Idiopathic CPP represents $90 \%$ of the cases in girls, whereas organic etiologies are more frequent $(60 \%$ to $70 \%)$ in boys. However, these epidemiological data are currently being revised with the new genetic and imaging diagnostic methods (8).

\section{Clinical diagnosis}

From a clinical standpoint, puberty onset and rate of progression are determined by the observation of physical changes. In girls, estrogen determines the deve-
Table 1. Etiologies of central precocious puberty

\begin{tabular}{l}
\hline Idiopathic \\
Genetic causes \\
Activating mutations in the KISS1R and KISS1 genes \\
Inactivating mutations in the MKRN3 gene (familial CPP) \\
Chromosomal abmormalities \\
Secondary to chronic exposure to sex steroid hormones (late treatment of \\
simple virilizing congenital adrenal hyperplasia, following ressection of tumors \\
secreting sex steroid hormones, testoxicosis, McCune-Albright syndrome) or \\
endocrine disruptors \\
International adoption \\
CNS abnormalities \\
Hypothalamic hamartoma \\
Tumors: astrocytoma, ependymoma, optic or hypothalamic glioma, \\
LH-secreting adenoma, pinealoma, neurofibroma, non-hCG secreting \\
dysgerminoma, craniopharyngioma* \\
Other congenital malformations: suprasellar cyst, arachnoid cyst, septo-optic \\
dysplasia, hydrocephalus, spina bifida, vascular malformation, \\
meningomyelocele, ectopic posterior pituitary lobe, pituitary duplication \\
Acquired diseases*: inflammatory processes (abscess, meningitis, \\
encephalitis, sarcoidosis, tuberculosis), radiation, perinatal asphyxia, trauma \\
\hline CNS: central nervosus system. ${ }^{*}$ May also progress to pituitary dysfunction.
\end{tabular}

CNS: central nervosus system. ${ }^{*}$ May also progress to pituitary dysfunction.

lopment of breasts, enlargement of labia majora and minora, and increase and redistribution of body fat predominantly in the hips. Another important aspect is the estrogenization of the vaginal epithelium, with acidification of the vaginal $\mathrm{pH}$ and mucus discharge. In response to testosterone, boys present testicular, penile, and cricoid cartilage growth (leading to voice change), facial hair development, changes in body fat distribution, and increase in muscle mass. In $40 \%$ of the boys, transient pubertal gynecomastia may occur. In both genders, development of pubic hair is associated with adrenarche (10,16-19). The stage of female and male pubertal development is determined by Marshall and Tanner's classification $(20,21)$.

To evaluate a patient with precocious puberty, the clinician must know the normal chronology of pubertal events and growth rate, and the progression of bone maturation (Figure 1) (22). A progression from one stage to another in less than six months and a height velocity above $6 \mathrm{~cm} /$ year characterize a progressive condition. Height, weight, and height velocity should be plotted in reference curves, and height is generally found to be above the familial pattern (10,16-19).

The main objective of evaluating patients with precocious puberty is to identify benign conditions from others caused by diseases like tumors, which require 

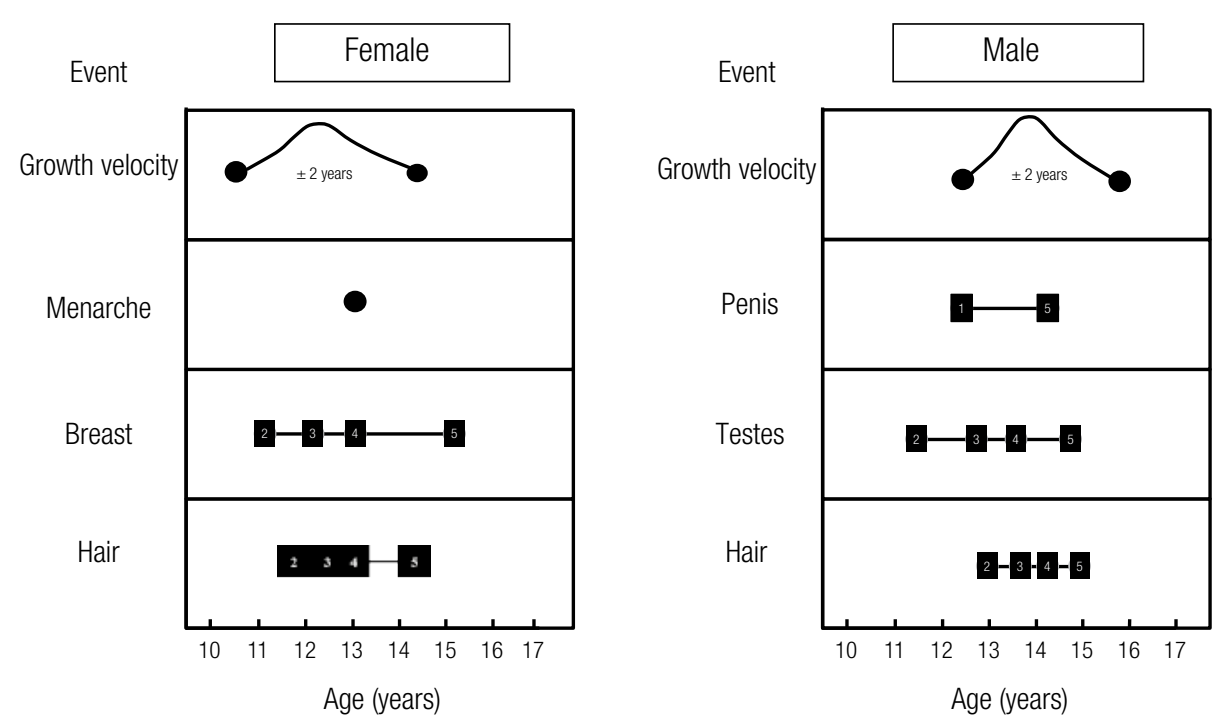

Figure 1. Chronology of sexual maturation and growth spurt during puberty in both genders according to Marshall \& Tanner (20,21) stages. Adapted from Tanner (22).

immediate and objective management. Patients with the following characteristics must always be evaluated:

- Early onset and/or accelerated development of secondary sexual characteristics in both genders;

- Height velocity above the expected value for gender and age and/or height above the familial genetic channel.

The clinical history must always be the initial diagnostic step, and investigation should include the birth conditions, history of perinatal trauma, previous infections, accidental ingestion of drugs, and use of creams or ointments. It is also very important to identify prior neurological diseases and information such as the occurrence of headache and psychological, visual, or appetite changes. The age at onset of signs and symptoms is not helpful in differential diagnosis. However, clinical manifestations below the age of 4 years suggest organic etiologies, particularly hypothalamic hamartomas. Information about family history, including the age at pubertal onset and similar cases in the family, may be useful in the diagnosis of familial CPP (10,16-19).

The physical examination must include information about height, weight, and pubertal stage. In girls, the differential diagnosis of CPP may be challenging because the spectrum of pubertal development is very broad and includes isolated premature thelarche, constitutional growth and puberty acceleration, progressive and nonprogressive CPP, and early puberty (develop- ment of secondary sexual characteristics between the ages of 8 and 9 years in girls and 9 and 10 years in boys) $(23,24)$. In boys, testicular development is often indicative of activation of the HPG axis, whereas in peripheral puberty, penile growth occurs without concomitant testicular development, or the size of the testis is disproportional to the virilization of the genitalia. Other important assessments during physical examination that may help in the differential diagnosis of idiopathic and neurogenic CPP include neurological examination, measurement of head circumference, and funduscopic evaluation. The physical examination must also investigate the presence of neurofibromas and café-au-lait spots with regular edges, which are suggestive of type 1 neurofibromatosis and related to CPP (associated with optic glioma). Café-au-lait spots with irregular and often jagged edges may indicate the diagnosis of McCune-Albright syndrome, which is associated with peripheral precocious puberty of ovarian etio$\operatorname{logy}(10,16-19)$.

\section{Differential diagnosis of precocious puberty}

It is essential to discriminate between CPP and common variants of precocious puberty, such as isolated premature thelarche or adrenarche and prepubertal vaginal bleeding due or not to a hormonal etiology. These conditions occur independent of the reactivation of gonadotropic axis. Premature thelarche refers to the isolated development of breast tissue, without other pu- 
bertal signs, such as accelerated linear growth and advanced bone age, without impairment of adult height. It usually regresses over several months. In the largest cohort on outcome of girls with premature thelarche, $13 \%$ of them developed progressive CPP (independent of the age of initial clinical presentation), which reinforce the need for long-term follow-up (25). Premature adrenarche is defined by the development of pubic or axillary hair growth due to increased concentrations of adrenal-derived androgens (mainly DHEA and DHEA sulfate). In this condition, adrenal disease (adrenal congenital hyperplasia, adrenocortical tumors) and other causes, such as contact with transdermal testosterone, topical corticosteroids cream, must be excluded. Advanced bone age might be present. Isolated prepubertal vaginal bleeding, with no other signs of puberty, are generally benign, acyclic and must be differentiated if it is dependent or not of hormonal action. Of note, prepubertal vaginal bleeding rarely represents the first manifestation of CPP. In addition, recurrent or continuous bleeding requires further investigation. Clinical indicators of pubertal progression should be carefully conducted in these patients with isolated forms. Laboratory and imaging assessment of isolated variants of puberty can be limited to basal hormonal levels, bone age and pelvic ultrasound in girls $(10,16,26)$.

\section{Laboratory diagnosis}

\section{Hormonal assessment}

Laboratory measurement of gonadotropins (mainly $\mathrm{LH})$ at baseline and/or after stimulation with short-acting $\mathrm{GnRH}$ is recommended to document the activation of the gonadal axis $(10,15)$. The sensitivity of serum $\mathrm{LH}$ at baseline morning for diagnosis of CPP, mainly in girls, varies between 60 and 100\%, depending on the cutoff value and laboratory methodology (16). Several laboratory methods with high sensitivity to measure gonadotropins levels are available, including immunofluorometric (IFMA), immunochemiluminescence (ICMA), and electrochemiluminescence (ECL). Of these, ICMA and ECL are the most commonly used. Basal LH values > 0.6 IU/L (IFMA) or $>0.3 \mathrm{IU} / \mathrm{L}$ (ICMA, ECL) in both genders are considered pubertal $(16,27,28)$. Although a basal $\mathrm{LH}$ value in the prepubertal range does not exclude the diagnosis of CPP, GnRH stimulation test is not warranted in most cases. Depending on clinical variables and their progression, a stimulation test with short-acting $\mathrm{GnRH}$ (intravenous gonadorelin, $100 \mu \mathrm{g}$ ) may be recommended. When short-acting GnRH is unavailable (which is frequent in Brazil), LH measurement 30 to 120 minutes after the first application of a monthly long-acting GnRH analog (GnRHa) may be an alternativeto confirm the biochemical diagnosis of CPP in clinically suspected cases $(29,30)$. The disadvantages of this strategy are the high cost, risk of local reaction and unavailability of GnRHa in some centers. For this reasons, the importance of basal $\mathrm{LH}$ in the diagnosis of CPP must be highlighted. A Canadian study demonstrated the ability of basal $\mathrm{LH}$, assessed by sensitive assay (ICMA), to predict clinical pubertal progression in 57 girls (31). Based on an algorithm, the authors found that a basal $\mathrm{LH}$ level $\geq 0.3 \mathrm{IU} / \mathrm{L}$ was indicative of pubertal progression while basal $\mathrm{LH} \leq 0.2 \mathrm{IU} / \mathrm{L}$ indicated no progression with $100 \%$ specifity and $90.5 \%$ sensitivity (31). The authors stated that basal LH levels in the diagnosis of CPP should be interpreted using local normative data and this approach may facilitate change in clinical practice avoiding the necessity of $\mathrm{GnRH}$ test, which is unfeasible in many centers, with cost savings (31). We demonstrated that basal $\mathrm{LH}>$ $0.6 \mathrm{U} / \mathrm{L}$, measured by IFMA, was able to diagnosis CPP in $62.7 \%$ of girls and $71.4 \%$ of boys (31). Using ICMA and ECLIA, we suggest consider the cutoff of basal $\mathrm{LH}$ of $0.3 \mathrm{U} / \mathrm{L}$ as indicative of CPP, avoiding the necessity of GnRH stimulation test. The distinct cutoff values of basal or GnRH-stimulated LH that indicate activation of the HPG axis are summarized in Table 2 $(27,28,30-38)$.

In girls, serum levels of $\mathrm{E} 2$ are not used to diagnose CPP, considering their low sensitivity and large overlap between normal prepubertal and pubertal children (26). In boys, serum total $\mathrm{T}$ is sensitive to diagnose precocious puberty but insufficient to determine the differential diagnosis between central and peripheral CPP, which is established from LH levels. Also in the male gender, measurement of $\beta$-hCG is always recommended. Measurement of basal or GnRH-stimulated FSH is not useful in the diagnosis of CPP, but when the levels are low or suppressed, they strongly suggest the diagnosis of peripheral precocious puberty (10). Levels of gonadotropins and sex steroid hormones in children below the age of 2 years should be interpreted with caution since they are often increased at this age in association with the physiological minipuberty. 
Table 2. Cutoff values of basal and GnRH-stimulated $\mathrm{LH}$ for diagnosis of central precocious puberty

\begin{tabular}{|c|c|c|c|c|}
\hline Author & Method & Basal LH (IU/L) & GnRH & LH peak after GnRH (IU/L) \\
\hline Neely and cols., 1995 (32) & ICMA & 0.15 & Gonadorelin 100 ug IV & 5.0 \\
\hline \multirow[t]{2}{*}{ Brito and cols., 1999 (27) } & IFMA & 0.6 & Gonadorelin 100 ug IV & $6.9(F)$ \\
\hline & & & & $9.6(\mathrm{M})$ \\
\hline Brito and cols., 2004 (30) & IFMA & 0.6 & Leuprorelin acetate $3.75 \mathrm{mg}$ & 10.0 \\
\hline \multirow[t]{2}{*}{ Houk and cols., 2009 (33) } & ICMA & 0.83 & N/A & N/A \\
\hline & IFMA & 1.05 & & \\
\hline Pasternak and cols., 2012 (34) & ICMA & 0.1 & Gonadorelin 100 ug IV & 4.9 \\
\hline Sathasivam and cols., 2010 (35) & ICMA & 0.3 & Leuprorelin acetate 20 ug/kg SC & 5.0 \\
\hline \multirow[t]{2}{*}{ Resende and cols., 2007 (28) } & ICMA & 0.2 & Gonadorelin 100 ug IV & $4.1(\mathrm{M}) ; 3.3(\mathrm{~F})$ \\
\hline & IFMA & 0.6 & & $3.3(\mathrm{M}) ; 4.2(\mathrm{~F})$ \\
\hline Lee and cols., 2013 (36) & ECLIA & 0.1 & Gonadorelin 100 ug IV & $5.0(F)$ \\
\hline \multirow[t]{2}{*}{ Freire and cols., 2013 (37) } & IFMA & $\mathrm{N} / \mathrm{A}$ & Triptorelin & 7.0 \\
\hline & ECLIA & & $0.1 \mathrm{mg} / \mathrm{m}^{2}$, maximum of $0.1 \mathrm{mg} \mathrm{SC}$ & 8.0 \\
\hline Bizarri and cols., 2014 (38) & ICMA & $>0.2$ & Gonadorelin 100 ug IV & 5.0 \\
\hline
\end{tabular}

ICMA: immunochemiluminescence; IFMA: immunofluorimetric; ECLIA: eletrochemiluminescence; SC: subcutaneous; IV: intravenous; F: female; M: male; N/A: not available.

\section{Ilmaging}

Bone age (BA) is obtained with an X-ray of the nondominant wrist and hand and estimated by different methods, of which Greulich and Pyle's is the most commonly used (39). In patients with precocious puberty, $\mathrm{BA}$ is often advanced, and when the advancement exceeds either one year or two standard deviations (SD), it is considered significant. BA is used to predict adult height by the Bayley-Pinneau method (40), although this method has low accuracy. Bayley-Pinneau tables for average BA should be preferred over those that use accelerated BA, since the latter overestimate adult height $(41,42)$. Pelvic ultrasonography is not used in the diagnosis of precocious puberty, but in girls, it helps determine the uterine and ovarian volume, and is a sensitive method to detect cysts and neoplastic lesions. An ovarian volume $>1.8 \mathrm{~mL}$ and uterine length $>3.4 \mathrm{~cm}$ indicate hormonal stimulation and may be an additional laboratory parameter to evaluate girls with precocious puberty (16). Microcysts and ovarian follicles are normal findings in approximately $40 \%$ of prepubertal girls. Some studies have demonstrated that pelvic ultrasonography and uterine artery Doppler findings are useful to establish a differential diagnosis between isolated premature thelarche and progressive CPP. This assessment is based on the pulsatility index (PI) of the uterine artery (a difference between the peak systolic and end-diastolic flow divided by the flow velocity). However, this method requires an experienced examiner
(43). After laboratory confirmation of CPP, anatomical assessment of the central nervous system (CNS) should be performed in all patients, preferably by magnetic resonance imaging (MRI) $(10,44)$. Computed tomography of the brain may identify CNS tumors, mainly calcified ones, but it has low sensitivity to detect small hamartomas.

\section{Molecular studies}

In all cases of idiopathic CPP with or without familial history, molecular study of the makorin ring-finger 3 (MKRN3) gene, recently implicated in the genetic etiology of CPP, is indicated and may elucidate the genetic basis of the CPP, with no implication on diagnosis and therapeutic management (26). MKRN3 has a potential inhibitory effect on $\mathrm{GnRH}$ secretion and inactivating $M K R N 3$ mutations have been identified in families from several geographical origins (12). In fact, MKRN3 represents the most common genetic cause of CPP (Table 1). In familial CPP, MKRN3 defects were found in about $30 \%$ of families (45) while in patients with apparently sporadic CPP, MKRN3 defects were detected in about $8 \%$ of cases (12). In theses cases, genetic counseling should be considered in affected patients and their families.

\section{Objectives and indications of pubertal arrest}

The treatment of precocious puberty aims to interrupt the sexual maturation until the normal age for pubertal development is reached, revert or stabilize the sexual 
characteristics, delay the skeletal maturation, preserve the normal height potential (within the range of the target height), avoid body disproportions, and promote the psychosocial adjustment of the patient and his or her family. It also helps to prevent pregnancy at an early age, and reduce the risk of sexual abuse, early initiation of sexual activity, and estrogen-dependent cancer (mainly breast cancer) related to the occurrence of early menarche $(10,44,46)$.

Pubertal arrest is indicated in patients with progressive precocious puberty of any etiology, accelerated pubertal development (progression from one pubertal stage to another in a shorter period than normal), potential of abnormal final stature [prediction of final height below the $2.5^{\text {th }}$ percentile; prediction of final height below the target height $( \pm 8.5 \mathrm{~cm})$; height SD for BA below -2 ; loss of height potential during follow-up (44)]. Clinical and anthropometric data and $\mathrm{BA}$ advance are crucial for the decision to treat or not CPP. A period of 3-6 months follow-up can be useful to evaluate the "progressive" pattern of CPP. There is no consensus about the recommendation of pubertal arrest exclusively for psychosocial reasons (behavioral disorders, emotional immaturity, mental retardation, seizures) (44). In early and fast puberty, pubertal arrest may be beneficial $(24,47)$.

\section{Treatment of central precocious puberty}

The treatment of choice for CPP is GnRHa $(15,44)$, a synthetic decapeptide that binds to the GnRH receptor in the pituitary with more stability and duration, and is resistant to protease degradation, which prolongs its half-life. GnRHa acts on the anterior pituitary, competing for $\mathrm{GnRH}$ receptor with endogenous GnRH, promoting endocytosis and reducing the amount of GnRH receptors (“down-regulation”) (46-48). Initially, GnRHa stimulates the synthesis and secretion of $\mathrm{LH}$ and FSH but when it is administered chronically, GnRHa suppresses the production of these hormones, which in turn suppress the production of sex steroid hormones by the gonads $(28,48)$. Of the available GnRHa, leuprorelin acetate (LA) and triptorelin are the most commonly used, and their efficacy and safety on the treatment of CPP has been demonstrated by several studies. The dose of GnRHa used to treat CPP is 75$100 \mu \mathrm{g} / \mathrm{kg}$. In practice, this corresponds to a $3.75 \mathrm{mg}$ administered intramuscularly or subcutaneously every 28 days. Although some American groups recommend higher GnRHa doses (200-300 $\mu \mathrm{g} / \mathrm{kg}$ ), a monthly $7.5 \mathrm{mg}$ dose has failed to show superior clinical results to initiate pubertal arrest (49). In recent years, more convenient preparations with trimonthly dosing became available, such as LA $11.25 \mathrm{mg}, 22.5 \mathrm{mg}$, and $30 \mathrm{mg}$, with several studies demonstrating their efficacy and safety compared with those of monthly GnRHa. However, long-term follow-up results are still lacking (49-51). In Brazil, the recent approval of 3-month depot LA 11.25 $\mathrm{mg}$ to treat CPP has improved dosing convenience and adherence, and brought satisfactory therapeutic results. Pubertal arrest may be initially obtained with 1-month depot (3.75 mg or $7.5 \mathrm{mg}$ ) or 3-month depot (11.25 $\mathrm{mg}$ ) dosages. A flowchart of CPP treatment is presented in Figure 2.

A subdermal implant of prolonged action that releases therapeutic doses of GnRHa for 12 to 24 months (histrelin $50 \mathrm{mg}$ ) has advantages and disadvantages over 1-month and 3-month depot GnRHa (52). The advantages include the abolishment of periodic subcutaneous or intramuscular administration, but the risk of reactions at the implant site, spontaneous extrusion, and local infection are the main undesirable side effects of this therapy. This treatment option is still unavailable in Brazil.

GnRHa are generally well tolerated, and their side effects are infrequent and include local allergic reactions ( $5 \%-10 \%$ of the cases), headache, abdominal pain, vaginal bleeding after the first GnRHa dose, nausea, vasomotor symptoms due to hypoestrogenism and hyperprolactinemia, and rarely, anaphylaxis $(10,44)$. These effects may be mild to severe in intensity. Attention should be given to local allergic reaction, characterized by the development of a sterile abscess, which impairs the absorption of GnRHa that fails to suppress the hormonal secretion (53). In these cases, medroxyprogesterone acetate (MPA) or cyproterone acetate (CPA) represent therapeutic options. Both MPA and $\mathrm{CPA}$ are useful in blocking puberty progression, but have no beneficial impact on final height. MPA inhibits central gonadotropin release by acting on hypothalamic pulse generator, and it also directly inhibits gonadal steroidigenesis by inhibiting 3 betahydroxysteroid dehydrogenase 2 enzyme $(16,19)$. In addition, MPA has a glucocorticoid mimetic action resulting in adrenocorticotrophic hormone (ACTH) suppression, hypertension, development of cushingoid habitus, and bone mineral loss. MPA dosage varies from $50 \mathrm{mg}$ to $150 \mathrm{mg}$ per month (depot intramuscular injection) 


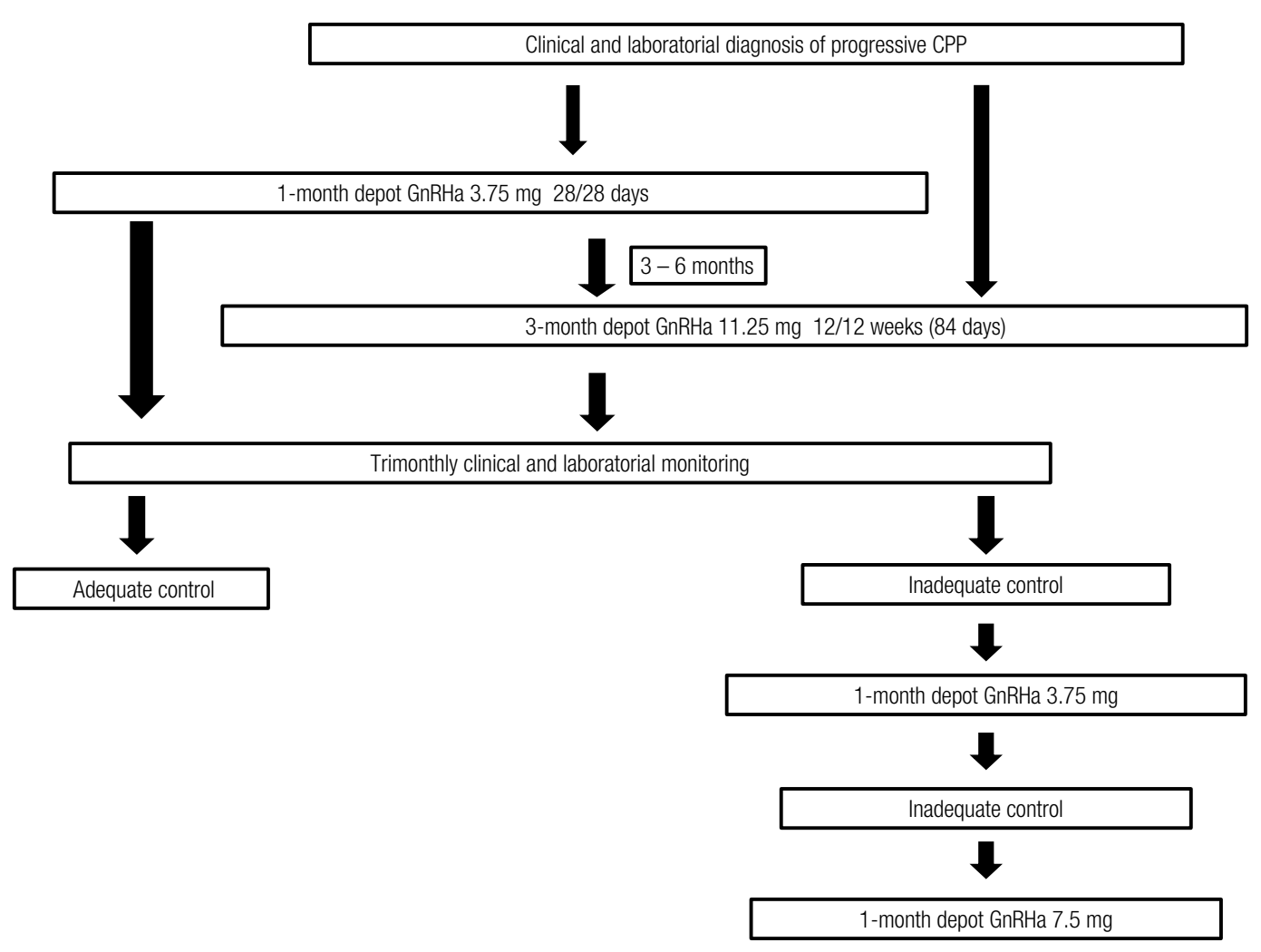

Figure 2. Treatment flowchart of progressive central precocious puberty (CPP) with a long-acting GnRH analog (GnRHa).

Advantages of MPA include its low cost, easily administration, and established efficacy in blocking puberty progression $(16,19)$. CPA has antiandrogenic activity, competing with testosterone for its receptor in peripheral tissues and an additional progestational action at the pituitary level, partially suppressing gonadotropin secretion. The usual CPA daily oral doses are 50 to 100 $\mathrm{mg} / \mathrm{m}^{2}(16)$. CPA side effects include gastrointestinal symptoms and gynecomastia in the male. Due to its ACTH and cortisol suppressing effect, laboratory hypoadrenalism can occur with CPA use, deserving special attention in stressful situation $(16,19)$. Of note, these therapeutic options must be considered only when GnRHa are not available or, as above-mentioned, in case of local reaction.

Surgical treatment of CNS lesions associated with CPP is indicated for both congenital and acquired malformations $(11,54)$. Other treatment modalities, such as chemotherapy or radiotherapy, are reserved for germ cell tumors. Treatment with surgery does not preclude clinical therapy with GnRHa $(10,11,15,54)$. Surgical therapy for hypothalamic hamartomas is reserved for large lesions associated with epilepsy refractory to clinical treatment, signs of intracranial hypertension, or rare cases of tumor growth, when a differential diagnosis must be established with other lesions, such as astrocytoma and glioma (55).

\section{Treatment monitoring in central precocious puberty}

The treatment of CPP with GnRHa is monitored by clinical and laboratory evaluations $(10,15)$. Parameters of good clinical control include stabilization or regression of secondary sexual characteristics, decrease in height velocity, and improvement in final height prediction. BA must be monitored annually in cases with adequate clinical and hormonal control, or semiannually in cases suggesting inadequate control. The laboratory parameter of choice is the measurement of $\mathrm{LH}$ values after monthly or trimonthly GnRHa, aiming at levels below $4 \mathrm{IU} / \mathrm{L}$ (determined by IFMA, ICMA, or ECL) $(10,16,28,29,50)$. Levels of E2 or T should be suppressed before GnRHa administration $(16,26,50)$. Patients with inadequate clinical and laboratory control that persists after an increase in GnRHa dose must have the etiological diagnosis of the precocious puberty carefully reevaluated $(10)$. When the height velocity reduces markedly (below $4 \mathrm{~cm} /$ year), recombinant human growth 
hormone ( $\mathrm{rGH}$ ) may be added to the treatment (56). This measure aims at increasing the height velocity and promoting height gain. The recommended $\mathrm{rGH}$ dose in this circumstance is $0.15 \mathrm{IU} / \mathrm{kg} /$ day administered subcutaneously. Few studies have assessed the impact of $\mathrm{rGH}$ administration on final height in patients with CPP (56-58). Two studies showed a benefit effect from adding $\mathrm{rGH}$ to GnRHa therapy in children with decreased growth during GnRHa therapy. In these nonrandomized studies, the mean final height was around $7.5 \mathrm{~cm}$ greater than the pretreatment predicted height $(56,57)$. In addition, 46 girls with early or precocious puberty adopted from developing countries were randomized for treatment for 2-4 y with GnRHa, or with a combination of rGH and GnRHa. During treatment, the mean growth velocity in the $\mathrm{rGH} / \mathrm{GnRHa}$ group was significantly higher and resulted in a higher final height (58). All in all, based on available literature, the association of $\mathrm{rGH}$ to $\mathrm{GnRH}$ cannot sistematically be recommended and the subset of CPP patients whose take some advantage with rGH addition was not determined so far $(44,58)$. Treatment withdrawal should take into account the chronological age of the patient and his or her psychosocial adequacy and desire. A BA around 12.5 years in girls and 13.5 years in boys indicate the best moment to withdraw the therapy aiming at reaching a normal final height within the genetic potential $(10,15,44,46)$.

\section{Long-term follow-up}

Final height, body composition, bone mineral density, reproductive function, and psychological characteristics are parameters of interest in the long-term follow-up of patients treated with GnRHa. Evidence shows that the GnRHa treatment is beneficial in preserving the potential genetic height, mainly in those girls who started treatement before 6 years of age $(42,44,46,47)$. Conversely, CPP diagnosed after the age of $6 \mathrm{yr}$ had reduced post treatment height gain and compromised final height, probably due to pre treatment intrinsic changes in the growth plate according Lazar and cols. $(24,47)$. In a Brazilian study involving 45 girls, we found no significant association between chronological age at the start of therapy and posttreatment linear growth (42). Although cronological age at the onset of therapy was significantly and negatively associated with final height, most of the girls who achieved normal adult height started GnRHa therapy after the age of $6 \mathrm{yr}$, indicating that GnRHa therapy is effective in preserving the potential genetic height in girls older than $6 \mathrm{yr}$ (42). In fact, the main factors determining normal final height in girls with CPP treated with depot GnRHa were shorter interval between the onset of puberty and onset of therapy, higher height SDS at the onset and end of therapy, and target height (42). Finally, no benefits on final height was demonstrated in those girls with early or fast puberty, although benefits on psychosocial profile and in delay menarche should be considered $(24,44,47)$.

Transitional changes in body composition and bone mass may occur without consequences in adulthood $(44,47,59)$. With regard to reproductive function, studies indicate that menstruation occurs on average 16 months after the treatment of CPP is withdrawn (with a variation of 2 to 61 months). Regular ovarian cycles occur in $60 \%$ to $96 \%$ of the patients, and infertility has not been reported $(44,59)$. In females, an increased prevalence of polycystic ovary syndrome has been reported, although the findings are controversial $(44,60)$. In males, a few studies that have been carried out have shown normal gonadal function (43). The few studies that have evaluated the psychosocial impact of CPP suggest that antisocial behavior is limited to adolescence and that there are no differences in psychosocial adjustment (44). However, there are no controlled studies evaluating the short- and long-term effects of the therapeutic intervention with GnRHa on psychosocial characteristics.

\section{CONCLUSIONS}

Puberty is a multifactorial process. The clinical diagnosis of precocious puberty is not always easy, particularly in females and among variants of normal development (premature thelarche and constitutional growth and puberty acceleration) with progressive and nonprogressive pathological conditions. The decision to treat CPP, mainly in girls, is based on clinical and anthropometric data, and bone age advance. Sometimes these data obtained at short-term follow-up do not recommend CPP treatment. Although the biochemical diagnosis has shown significant improvement with more sensitive and specific immunoassays, standardization is still required due to the availability of several methods and protocols to measure basal and GnRH-stimulated LH. This fact results in different cutoff values to confirm the activation of the gonadal axis. Treatment with GnRHa has shown significant advances in recent years, with more convenient, effective, and safe dosages in the short- and long-term. 
Disclosure: all authors received lecture fees from Abbvie. No potential conflict of interest relevant to this article was reported.

\section{REFERENCES}

1. Palmert MR, Boepple PA. Variation in the timing of puberty: clinical spectrum and genetic investigation. J Clin Endocrinol Metab. $2001 ; 86(6): 2364-8$

2. Ojeda SR, Dubay C, Lomniczi A, Kaidar G, Matagne V, Sandau US, et al. Gene networks and the neuroendocrine regulation of puberty. Mol Cell Endocrinol. 2010;324:3-11.

3. Grumbach MM. The neuroendocrinology of human puberty revisited. Horm Res. 2002;57(Suppl 2):2-14.

4. Idkowiak J, Lavery GG, Dhir V, BarrettTG, Stewart PM, Krone N, et al. Premature adrenarche: novel lessons from early onset androgen excess. Eur J Endocrinol. 2011;165:189-207.

5. Herman-Giddens ME, Slora EJ, Wasserman RC, Bourdony CJ, Bhapkar MV, Koch GG, et al. Secondary sexual characteristics and menses in young girls seen in office practice: a study from the Pediatric Research in Office Settings network. Pediatrics. 1997;99(4):505-12.

6. Feibelmann TCM, Adriana, Silva AP, Resende DCS, Resende EAMR, Scatena LM, et al. Puberty in a sample of Brazilian schoolgirls: timing and anthropometric characteristics. Arq Bras Endocrinol Metab. 2015;59(2):105-11.

7. Mogensen SS, Aksglaede L, Mouritsen A, Sørensen K, Main KM, Gideon $\mathrm{P}$, et al. Diagnostic work-up of 449 consecutive girls who were referred to be evaluated for precocious puberty. J Clin Endocrinol Metab. 2011;96(5):1393-401.

8. Herman-Giddens ME, Steffes J, Harris D, Slora E, Hussey M, Dowshen SA, et al. Secondary sexual characteristics in boys: data from the Pediatric Research in Office Settings network. Pediatrics. 2012;130(5):e1058-68.

9. Alikasifoglu A, Vuralli D, Gonc EN, Ozon A, Kandemir N. Changing etiological trends in male precocious puberty: evaluation of 100 cases with central precocious puberty over the last decade. Horm Res Paediatr. 2015;83(5):340-4.

10. Macedo DB, Cukier P, Mendonça BB, Latronico AC, Brito VN. Avanços na etiologia, no diagnóstico e no tratamento da puberdade precoce central. Arq Bras EndocrinolMetab. 2014;58(2):108-17.

11. Stephen MD, Zage PE, Waguespack SG. Gonadotropin-dependent precocious puberty: neoplastic causes and endocrine considerations. Int J Pediatr Endocrinol. 2011;2011:184502.

12. Bulcao Macedo D, Nahime Brito V, Latronico AC. New causes of central precocious puberty: the role of genetic factors. Neuroendocrinology. 2014;100(1):1-8.

13. Teilmann G, Pedersen CB, Skakkebaek NE, Jensen TK. Increased risk of precocious puberty in internationally adopted children in Denmark. Pediatrics. 2006;118(2):e391-9.

14. Mouritsen A, Aksglaede L, Sorensen K, Mogensen SS, Leffers $H$, Main KM, et al. Hypothesis: exposure to endocrine-disrupting chemicals may interfere with timing of puberty. Int J Androl. 2010;33(2):346-59.

15. Fuqua JS. Treatment and outcomes of precocious puberty: an update. J Clin Endocrinol Metab. 2013;98(6):2198-207.

16. Brito VN, Latronico AC, Arnhold IJ, Mendonça BB. Update on the etiology, diagnosis and therapeutic management of sexual precocity. Arq Bras Endocrinol Metabol. 2008;52(1):18-31.

17. Carel JC, Léger J. Clinical practice. Precocious puberty. N Engl J Med. 2008;358(22):2366-77.

18. Berberoğlu M. Precocious puberty and normal variant puberty: definition, etiology, diagnosis and current management. J Clin Res Pediatr Endocrinol. 2009;1(4):164-74.
19. Kumar M, MukhopadhyayS, Dutta D. Challenges and controversies in diagnosis and management of gonadotropin dependent precocious puberty: an Indian perspective. Indian $\mathrm{J}$ Endocrinol Metab. 2015;19(2):228-35.

20. Marshall WA, Tanner JM. Variations in pattern of puberal changes in girls. Arch Dis Child. 1969;44:291-303.

21. Marshall WA, Tanner JM. Variations in the pattern of pubertal changes in boys. Arch Dis Child. 1970;45:13-23.

22. Tanner JM. Growth and endocrinology of the adolescent. In: Gardner LI (ed). Endocrine and genetic diseases of childhood and adolescents. Philadelphia, WB: Saunders, 1975.

23. Papadimitriou A, Nicolaidou P, Fretzayas A, Chrousos GP. Clinical review: constitutional advancement of growth, a.k.a. early growth acceleration, predicts early puberty and childhood obesity. J Clin Endocrinol Metab. 2010;95(10):4535-41.

24. Lazar L, Kauli R, Pertzelan A, Phillip M. Gonadotropin-suppressive therapy in girls with early and fast puberty affects the pace of puberty but not total pubertal growth or final height. J Clin Endocrinol Metab. 2002;87(5):2090-4.

25. de Vries L, Guz-Mark A, Lazar L, Reches A, Phillip M. Premature thelarche: age at presentation affects clinical course but not clinical characteristics or risk to progress to precocious puberty. J Pediatr. 2010;156(3):466-71.

26. Latronico AC, Brito VN, Carel JC. Causes, diagnosis, and treatment of central precocious puberty. Lancet Diabetes Endocrinol. 2016 Feb 3. pii: S2213-8587(15)00380-0.

27. Brito VN, Batista MC, Borges MF, Latronico AC, Kohek MB, Thirone $A C$, et al. Diagnostic value of fluorometric assays in the evaluation of precocious puberty. J Clin Endocrinol Metab. 1999;84(10):3539-44.

28. Resende EA, Lara BH, Reis JD, Ferreira BP, Pereira GA, Borges MF. Assessment of basal and gonadotropin-releasing hormonestimulated gonadotropins by immunochemiluminometric and immunofluorometric assays in normal children. J Clin Endocrinol Metab. 2007;92(4):1424-9.

29. Bhatia S, Neely EK, Wilson DM. Serum luteinizing hormone rises within minutes after depot leuprolide injection: implications for monitoring therapy. Pediatrics. 2002;109:E30.

30. Brito VN, Latronico AC, Arnhold IJ, Mendonca BB. A single luteinizing hormone determination 2 hours after depot leuprolide is useful for therapy monitoring of gonadotropin-dependent precocious puberty in girls. J Clin Endocrinol Metab. 2004;89(9):4338-42.

31. Harrington J, Palmert MR, Hamilton J. Use of local data to enhance uptake of published recommendations: an example from the diagnostic evaluation of precocious puberty. Arch Dis Child. 2014; 99(1):15-20.

32. Neely EK, Hintz RL, Wilson DM, Lee PA, Gautier T, Argente J, et al. Normal ranges for immunochemiluminometric gonadotropin assays. J Pediatr. 1995;127(1):40-6.

33. Houk CP, Kunselman AR, Lee PA. Adequacy of a single unstimulated luteinizing hormone level to diagnose central precocious puberty in girls. Pediatrics. 2009;123:e1059-63.

34. Pasternak Y, Friger M, Loewenthal N, Haim A, Hershkovitz E. The utility of basal serum $\mathrm{LH}$ in prediction of central precocious puberty in girls. Eur J Endocrinol. 2012;166:295-9.

35. Sathasivam A, Garibaldi L, Shapiro S, Godbold J, Rapaport R. Leuprolide stimulation testing for the evaluation of early female sexual maturation. Clin Endocrinol (Oxf). 2010;73(3):375-81.

36. Lee DS, Ryoo NY, Lee SH, Kim S, Kim JH. Basal luteinizing hormone and follicular stimulating hormone: is it sufficient for the diagnosis of precocious puberty in girls? Ann Pediatr Endocrinol Metab. 2013;18:196-201.

37. Freire AV, Escobar ME, Gryngarten MG, Arcari AJ, Ballerini MG, Bergada I, et al. High diagnostic accuracy of subcutaneous trip- 
torelin test compared with GnRH test for diagnosing central precocious puberty in girls. Clin Endocrinol (Oxf). 2013;78(3):398-404.

38. Bizzarri C, Spadoni GL, Bottaro G, Montanari G, Giannone G, Cappa $\mathrm{M}$, et al.The response to gonadotropin releasing hormone ( $\mathrm{GnRH}$ ) stimulation test does not predict the progression to true precocious puberty in girls with onset of premature thelarche in the first three years of life. J Clin Endocrinol Metab. 2014;99(2):433-9.

39. Greulich WW, Pyle SI. Radiographic atlas of skeletal development of the hand and wrist. Stanford: Stanford University Press, 1959.

40. Bayley N, Pinneau S. Tables for predicting adult height from skeletal age. J Pediatr. 1952;14:432-41.

41. Kauli R, Galatzer A, Kornreich L, Lazar L, Pertzelan A, Laron Z. Final height of girls with central precocious puberty, untreated versus treated with cyproterone acetate or $\mathrm{GnRH}$ analogue. A comparative study with re-evaluation of predictions by the Bayley-Pinneau method. Horm Res. 1997;47:54-61.

42. Brito VN, Latronico AC, Cukier P, Teles MG, Silveira LF, Arnhold $\mathrm{IJ}$, et al. Factors determining normal adult height in girls with gonadotropin-dependent precocious puberty treated with depot gonadotropin-releasing hormone analogs. J Clin Endocrinol Metab. 2008;93(7):2662-9.

43. Battaglia C, Mancini F, Regnani G, Persico N, lughetti L, De Aloysio D. Pelvic ultrasound and color Doppler findings in different isosexual precocities. Ultrasound Obstet Gynecol. 2003;22(3):277-83.

44. Carel JC, Eugster EA, Rogol A, Ghizzoni L, Palmert MR; ESPELWPES GnRH Analogs Consensus Conference Group, et al. Consensus statement on the use of gonadotropin-releasing hormone analogs in children. Pediatrics. 2009;123(4):e752-62.

45. Abreu AP, Dauber A, Macedo DB, Noel SD, Brito VN, Gill JC, et al. Central precocious puberty caused by mutations in the imprinted gene MKRN3. N Engl J Med. 2013;368(26):2467-75.

46. Heger S, Sippell WG, Partsch CJ. Gonadotropin-releasing hormone analogue treatment for precocious puberty. Twenty years of experience. Endocr Dev. 2005;8:94-125.

47. Lazar L, Padoa A, Phillip M. Growth pattern and final height after cessation of gonadotropin-suppressive therapy in girls with central sexual precocity. J Clin Endocrinol Metab. 2007;92(9):3483-9.

48. Lahlou N, Carel JC, Chaussain JL, Roger M. Pharmacokinetics and pharmacodynamics of $\mathrm{GnRH}$ agonists: clinical implications in pediatrics. J Pediatr Endocrinol Metab. 2000;13:723-37.

49. Mostafa NM, Hosmane B, Larsen LM, Chwalisz K, Chiu YL, Pradhan RS. Pharmacokinetic and exposure-response analyses of leuprolide following administration of leuprolide acetate 3-month depot formulations to children with central precocious puberty. Clin Drug Investig. 2014;34(7):441-8.
50. Badaru A, Wilson DM, Bachrach LK, Fechner P, Gandrud LM, Durham $E$, et al. Sequential comparisons of one-month and threemonth depot leuprolide regimens in central precocious puberty. J Clin Endocrinol Metab. 2006;91:1862-7.

51. Lee PA, Klein K, Mauras N, Lev-VaislerT, Bacher P. 36-month treatment experience of two doses of leuprolide acetate 3-month depot for children with central precocious puberty. J Clin Endocrinol Metab. 2014;99(9):3153-9.

52. Silverman LA, Neely EK, Kletter GB, Lewis K, Chitra S, Terleckyj $O$, et al. Long-term continuous suppression with once-yearly histrelin subcutaneous implants for the treatment of central precocious puberty: a final report of a phase 3 multicenter trial. J Clin Endocrinol Metab. 2015;100(6):2354-63.

53. Yasukawa K, Sawamura D, Sugawara H, Kato N. Leuprorelin acetate granulomas: case reports and review of the literature. $\mathrm{Br} \mathrm{J}$ Dermatol. 2005;152(5):1045-7.

54. Trivin C, Couto-Silva AC, Sainte-Rose C, Chemaitilly W, Kalifa C, Doz $F$, et al. Presentation and evolution of organic central precocious puberty according to the type of CNS lesion. Clin Endocrinol (Oxf). 2006;65(2):239-45.

55. Pati S, Sollman M, Fife TD, NgYT. Diagnosis and management of epilepsy associated with hypothalamic hamartoma: an evidencebased systematic review. J Child Neurol. 2013;28(7):909-16.

56. Pasquino AM, Municchi G, Pucarelli I, Segni M, Mancini MA, Troiani S. Combined treatment with gonadotropin-releasing hormone analog and growth hormone in central precocious puberty. J Clin Endocrinol Metab. 1996; 81:948-51.

57. Pucarelli I, Segni M, Ortore M, Arcadi E, Pasquino AM. Effects of combined gonadotropin-releasing hormone agonist and growth hormone therapy on adult height in precocious puberty: a further contribution. J Pediatr Endocrinol Metab. 2003;16(7):1005-10.

58. Tuvemo T, Jonsson B, Gustafsson J, Albertsson-Wikland K, Aronson AS, Häger $A$, et al. Final height after combined growth hormone and $\mathrm{GnRH}$ analogue treatment in adopted girls with early puberty. Acta Paediatr. 2004;93(11):1456-62.

59. Pasquino AM, Pucarelli I, Accardo F, Demiraj V, Segni M, Di Nardo R. Long-term observation of 87 girls with idiopathic central precocious puberty treated with gonadotropin-releasing hormone analogs: impact on adult height, body mass index, bone mineral content, and reproductive function. J Clin Endocrinol Metab. 2008;93(1):190-5.

60. Franceschi R, Gaudino R, Marcolongo A, Gallo MC, Rossi L, Antoniazzi $F$, et al. Prevalence of polycystic ovary syndrome in young women who had idiopathic central precocious puberty. Fertil Steril. 2010;93(4):1185-91. 


\section{Central precocious puberty: revisiting the diagnosis and therapeutic management}

Vinícius Nahime Brito, Angela Maria Spinola-Castro, Cristiane Kochi, Cristiane Kopacek, Paulo César Alves da Silva, Gil Guerra-Júnior

Arch Endocrinol Metab. 2016;60(2):163-72

DOI: 10.1590/2359-3997000000144

Where you read:

\section{INTRODUCTION}

D uberty is a period of physical, hormonal, and psychological transition from childhood to adulthood, with accelerated linear growth and achievement of reproductive function. It is a complex and multifactorial process that includes genetic, metabolic, environmental, ethnic, geographic, and economic factors and results in reactivation of the hypothalamic-pituitary-gonadal (HPG) axis. An effective pubertal onset requires pulsatile hypothalamic secretion of $\mathrm{GnRH}$ stimulating the secretion of gonadotropins by the anterior pituitary gland $(\mathrm{LH}=$ luteinizing hormone and $\mathrm{FSH}=$ follicle-stimulating hormone). Gonadotropins stimulate the gonads and exert a negative feedback effect on the hypothalamus, whereas gonadal steroids ( $\mathrm{T}=$ testosterone, produced by the testis, and E2 = estradiol, produced by the ovaries) inhibit both hypothalamus and anterior pituitary gland. This process is named gonadarche (1-3).
Should read:

\section{INTRODUCTION}

D uberty is a period of physical, hormonal, and psychological transition from childhood to adulthood, with accelerated linear growth and achievement of reproductive function. It is a complex and multifactorial process that includes genetic, metabolic, environmental, ethnic, geographic, and economic factors and results in reactivation of the hypothalamicpituitary-gonadal (HPG) axis. An effective pubertal onset requires pulsatile hypothalamic secretion of $\mathrm{GnRH}$ stimulating the secretion of gonadotropins by the anterior pituitary gland $(\mathrm{LH}=$ luteinizing hormone and $\mathrm{FSH}=$ follicle-stimulating hormone). Gonadotropins stimulate the gonads, whereas gonadal steroids ( $\mathrm{T}=$ testosterone, produced by the testis, and $\mathrm{E} 2$ = estradiol, produced by the ovaries) inhibit both hypothalamus and anterior pituitary gland. This process is named gonadarche (1-3). 